\title{
Reducing drying shrinkage of concrete by treatment of aggregate
}

\author{
A. K. H. Kwan, W. W. S. Fung and H. H. C. Wong
}

The University of Hong Kong

Drying shrinkage of concrete has been found to cause cracking, water leakage and other serviceability problems and is thus an important research topic. In early studies, it has been found that the shrinkage of concrete varies with the rock aggregate used. This is partly because the aggregate also shrinks and the shrinkage of aggregate is dependent on the type of rock from which the aggregate is derived. However, there have been few studies on the shrinkage of rock and how the shrinkage of aggregate would affect the shrinkage of concrete. In this study, the shrinkage of the granite rock in Hong Kong was measured. It has been found that the rock shrinks quite substantially upon drying and that its shrinkage is dependent on the initial moisture condition. Based on such observation, two alternative methods of treating the aggregate before use so as to reduce the shrinkage of concrete are proposed. Long-term shrinkage measurement of concrete made with untreated and treated aggregates revealed that the proposed methods of aggregate treatment, which are still rudimentary, can significantly reduce the shrinkage of concrete.

\section{Introduction}

Concrete shrinks as it dries during and after hardening. This will lead to significant shortening movement of the concrete structure and, if the shortening movement is restrained by rigid supports, cracking of the concrete structure. The shrinkage cracks so formed often cause aesthetic, water leakage and other serviceability problems. In the long run, they will also cause durability problems. One common way of alleviating shrinkage cracking is to relieve the movement restraints so as to allow unrestrained shrinkage movement by the provision of movement joints or late-cast strips (Kim and Cho, 2004; Kwan et al., 2002). However, architects hate movement joints, which limit the function of the structure, and contractors hate late-cast strips, which cause delay of the construction. In this regard, perhaps one possible better solution is to reduce the shrinkage of concrete - the root cause of these problems. The possibility of reducing the shrinkage of concrete is of course yet to be investigated; most engineers regard the shrinkage of concrete as an unavoidable natural phenomenon and have never considered such a possibility.

Department of Civil Engineering, The University of Hong Kong, Pokfulam Road, Hong Kong, People's Republic of China

(MACR 900019). Paper received 29 January 2009; last revised 10 July 2009; accepted 3 September 2009.
Although there has been extensive research on the shrinkage of concrete (Ayano and Wittmann, 2002; Barr et al., 2003; Bazant et al., 1987; Bissonnette et al., 1999; Bloom and Bentur, 1995; Hansen and Almudaiheem, 1987), the mechanism of concrete shrinkage is still not fully understood. Nevertheless, it is now generally accepted that the major factors affecting the shrinkage of concrete include at least the aggregate properties, aggregate content, water content, cementitious materials, curing conditions, environmental conditions and member size and shape. A number of shrinkage models for prediction of concrete shrinkage have been given in British Standard BS 5400 (BSI, 1990), CEB-FIP Model Code (CEB-FIP, 1993), Eurocode 2 (BSI, 2004) and ACI code 209.2R-08 (ACI, 2008). However, they consider different factors and do not quite agree with each other. Somehow, they all have the common feature of ignoring the possible effects of the type of aggregate used, which can be quite significant (Alexander and Mindess, 2005). On the other hand, the shrinkage of Hong Kong concrete has been found to be substantially larger than that predicted by any of the existing codified shrinkage models (Highways Department, 2002, 2006; Kwan et al., 2010). The authors are of the view that the relatively high water absorption and relatively low elastic modulus of the local granite aggregate (Lee et al., 2000) are both contributing factors to the large shrinkage of Hong Kong concrete. Furthermore, they suspect 
that the aggregate may also shrink when the concrete dries and the shrinkage of the aggregate is another contributing factor to the large shrinkage of Hong Kong concrete.

There has been little research on the shrinkage of granite rock and thus whether the local granite aggregate would also shrink when the concrete dries has been a controversial issue. To resolve this, the present authors have decided to measure the shrinkage of granite rock cores obtained locally. As will be reported in the present study, the results revealed that the shrinkage of the local granite rock could amount to $380 \mu \varepsilon$ (note; $1 \mu \varepsilon=1 \times 10^{-6}$ ) and that the shrinkage of the granite rock is dependent on the initial moisture condition. This settles the long-term controversy and explains why the shrinkage of Hong Kong concrete is so large. More importantly, the initial moisture condition of the rock aggregate, which has been ignored by most other researchers, is also a factor affecting the shrinkage of concrete.

Taking a step further, the current authors are considering the possibility of reducing the shrinkage of concrete by controlling the initial moisture condition of the rock aggregate. As the shrinkage of rock aggregate is larger when the aggregate is wet and smaller when the aggregate is dry before being added to the concrete mix, one simple way of reducing the shrinkage of concrete is to dry the aggregate before use. However, since the aggregate would become wet again after mixing with the water in the concrete mix, such simple drying is expected to have limited effectiveness. For higher effectiveness, the authors are proposing in this study to treat the aggregate before drying by immersion in polymer latex or water repellent, which fills the pores in the aggregate to block or slow down water ingress when the aggregate is added to the concrete mix.

In the present paper, the results of a testing programme that aims to measure the shrinkage of the local granite rock and the shrinkage of concrete made with untreated and treated granite aggregates are reported. It will be seen that the proposed aggregate treatment could be an emerging technology for reducing concrete shrinkage and alleviating shrinkage cracking of concrete structures.

\section{Testing programme}

The testing programme comprised two parts, termed part A and part B. Part A was to measure the shrinkage of the local granite rock under different initial moisture conditions, whereas part $\mathrm{B}$ was to measure the shrinkage of concrete made with granite aggregate from the same source, but with different treatment applied.

For part A, granite rock cores obtained locally from ground investigation works were tested. All the rock cores were from the same source. They have the same diameter of $60 \mathrm{~mm}$ and were cut into $250 \mathrm{~mm}$ length specimens for the shrinkage tests. The rock core specimens were divided into four groups, each comprising three specimens. The four groups were termed RC1, $\mathrm{RC} 2, \mathrm{RC} 3$ and RC4, and the three specimens in each group were termed (a), (b) and (c).

The rock cores in $\mathrm{RC} 1$ were untreated and simply stored in the laboratory at a temperature of $22-27^{\circ} \mathrm{C}$ and a relative humidity of $60-75 \%$ for 1 month so that their initial moisture condition may be described as 'as supplied'. For the rock cores in RC2, water immersion was applied by immersing them in a water bath at a temperature of $27^{\circ} \mathrm{C}$ for 7 days. For the rock cores in $\mathrm{RC} 3$, vacuum saturation was applied by immersing them in water inside a vacuum chamber at a pressure lower than $0 \cdot 1$ of the atmospheric pressure and a temperature of $27^{\circ} \mathrm{C}$ for 1 day. Finally, for the rock cores in $\mathrm{RC} 4$, drying was applied by putting them into a condition chamber set at a temperature of $50^{\circ} \mathrm{C}$ and a relative humidity of $50 \%$ for 7 days.

After the above treatment, all the rock cores were immersed in water for $6 \mathrm{~h}$ at $27^{\circ} \mathrm{C}$ to simulate the wetting and water absorption of the rock aggregate while the concrete is still fresh. Having been immersed in water for $6 \mathrm{~h}$, the rock cores were then put into a condition chamber maintained at a temperature of $27 \pm 2{ }^{\circ} \mathrm{C}$ and a relative humidity of $50 \pm 2 \%$ for shrinkage tests.

For part B, concrete mixes made with the local granite aggregate were cast for shrinkage testing. All the aggregates, including the fine aggregate, $10 \mathrm{~mm}$ aggregate and $20 \mathrm{~mm}$ aggregate, were from the same source. They were divided into six groups, each treated differently before use. The six groups were termed A1, A2, A3, A4, B1 and B2. The aggregates in A1, A2, A3 and $\mathrm{A} 4$ were treated in exactly the same ways as the rock cores in $\mathrm{RC} 1, \mathrm{RC} 2, \mathrm{RC} 3$ and $\mathrm{RC} 4$, respectively, whereas the aggregates in B1 and B2 were treated by the proposed treatment methods.

Table 1 summarises the treatment applied to the six groups of aggregate. For the aggregates in B1, they were first immersed in a $20 \%$ solution of Ronafix ${ }^{\mathrm{TM}}$ (a polymer latex) for $6 \mathrm{~h}$, rinsed by clean water for $15 \mathrm{~min}$ and then dried in a condition chamber at a temperature of $50^{\circ} \mathrm{C}$ and a relative humidity of $50 \%$ for 7 days. For the aggregates in B2, they were first immersed in a $0.6 \%$ solution of Darapel ${ }^{\mathrm{TM}}$ (a water repellent) for $6 \mathrm{~h}$, rinsed by clean water for $15 \mathrm{~min}$ and then dried in a

Table 1. Treatment applied to aggregate

\begin{tabular}{l|l}
\hline $\begin{array}{l}\text { Aggregate } \\
\text { designation }\end{array}$ & Treatment applied \\
\hline A1 & As supplied \\
A2 & Water immersion \\
A3 & Vacuum saturation \\
A4 & Drying at $50^{\circ} \mathrm{C}$ \\
B1 & Immersion in polymer latex for $6 \mathrm{~h}$ before drying \\
B2 & Immersion in water repellent for $6 \mathrm{~h}$ before drying \\
\hline
\end{tabular}

Magazine of Concrete Research, 2010, 62, No. 6 
condition chamber at a temperature of $50^{\circ} \mathrm{C}$ and a relative humidity of $50 \%$ for 7 days. (The product information for Ronafix and Darapel may be obtained from the websites www.ronacrete.com and www. graceconstruction.com, respectively.) To study the effects of such treatments on the water absorption of the aggregates, the water absorption values of the aggregates in A1, B1 and B2, that is the aggregates before and after treatment, were measured in accordance with the method given in BS 812: Part 2: 1995 (BSI, 1995).

Six concrete mixes, all of grade 40 , were cast from the aggregates. They have the same mix proportions, as presented in Table 2, but were each made with aggregates that had been treated differently. The concrete mixes were termed CON1, CON2, CON3, CON4, CON5 and CON6, and were made with aggregates from A1, A2, A3, A4, B1 and B2, respectively. From each concrete mix, three cubes, termed (1), (2) and (3), were cast for compressive strength tests and four prisms, termed (i), (ii), (iii) and (iv), were cast for shrinkage tests. The cubes were of size $150 \times$ $150 \times 150 \mathrm{~mm}$ and the prisms were of size $75 \times 75 \times$ $250 \mathrm{~mm}$. Steel moulds were used for casting of these specimens. Immediately after casting, the trowelled surfaces of the specimens were covered with plastic sheets so that all surfaces of the specimens were protected from drying. The specimens were demoulded $24 \mathrm{~h}$ after casting. Then, the cubic specimens were cured in a lime-saturated water tank at a temperature of $27 \pm 2^{\circ} \mathrm{C}$ until the age of 28 days and the prismatic specimens were cured by covering with wet hessian at room temperature (within $22-27^{\circ} \mathrm{C}$ ) until the age of 7 days.

After the curing period, each prismatic specimen was coated at the two end surfaces and the top and bottom surfaces by an impermeable polymer-latex-impregnated cement mortar so that only the two side surfaces would be subjected to drying. With only the two side surfaces subjected to drying, the effective thickness of the prismatic specimen is the same as the breadth, that is $75 \mathrm{~mm}$. Having been coated, the prismatic specimens were put into a condition chamber maintained at a temperature of $27 \pm 2{ }^{\circ} \mathrm{C}$ and a relative humidity of $50 \pm 2 \%$ for shrinkage tests.

The shrinkage strains of the rock cores and the concrete prisms were measured using the apparatus stipulated in BS 812: Part 120: 1989 (BSI, 1989). During the first month, the shrinkage strains were measured every day and thereafter, as the shrinkage slowed down, the shrinkage strains were measured at successively reduced frequency up to at least 600 days of drying.

Altogether, 12 rock cores and 24 concrete prisms have been tested for their shrinkage, 18 concrete cubes have been tested for their compressive strength and 18 aggregate samples have been tested for their water absorption. Overall, the testing programme lasted over 3 years.

\section{Shrinkage of rock}

The shrinkage-time curves of the rock cores in the groups $\mathrm{RC} 1$ and $\mathrm{RC} 2$, and the rock cores in the groups $\mathrm{RC} 3$ and RC4, are presented in Figures 1 and 2, respectively. For each group of rock cores, the shrinkagetime curves of all three rock cores having the same treatment applied and the same initial moisture condition are plotted in these figures. In all cases, the shrinkage-time curves of the rock cores in the same group are fairly close to each other, with differences in the measured shrinkage strain generally less than $50 \mu \varepsilon$. Hence, it may be said that the measured results are reasonably consistent. For easier interpretation, the shrinkage strains of the three rock cores in each group are averaged to yield the average shrinkage-time curves of the four groups of rock cores in Figure 3.

From the shrinkage-time curves plotted, it can be seen that, in general, the shrinkage increased with time initially at a rapid rate and then at a gradually decreasing rate until after several months the shrinkage increased only marginally with time. Basically, after a year or so, the shrinkage became quite steady. From

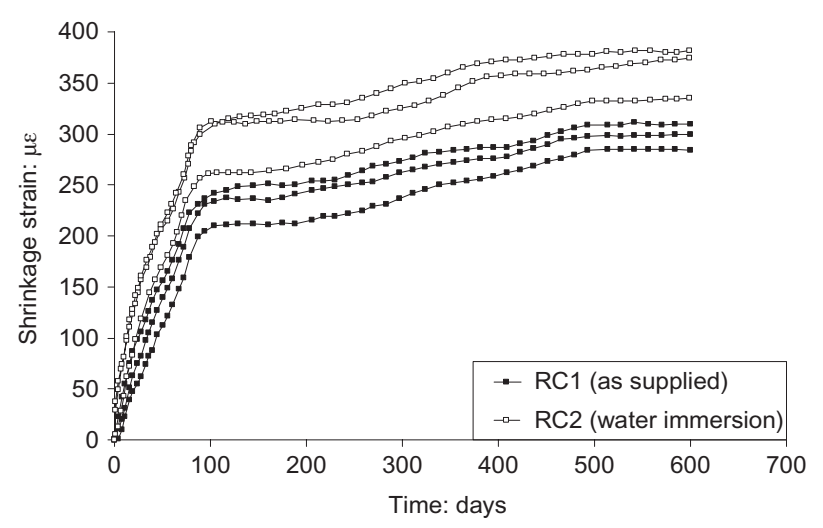

Figure 1. Shrinkage of rock cores $R C 1$ and $R C 2$

Table 2. Concrete mix proportions

\begin{tabular}{c|c|c|c|c|c|c}
\hline Grade: $\mathrm{MPa}$ & $\begin{array}{c}\text { Paste volume: } \\
\%\end{array}$ & $\begin{array}{c}\text { Water content: } \\
\mathrm{kg} / \mathrm{m}^{3}\end{array}$ & $\begin{array}{c}\text { Cement content: } \\
\mathrm{kg} / \mathrm{m}^{3}\end{array}$ & $\begin{array}{c}\text { Fine aggregate: } \\
\mathrm{kg} / \mathrm{m}^{3}\end{array}$ & $\begin{array}{c}10 \mathrm{~mm} \text { aggregate: } \\
\mathrm{kg} / \mathrm{m}^{3}\end{array}$ & $\begin{array}{c}20 \mathrm{~mm} \text { aggregate: } \\
\mathrm{kg} / \mathrm{m}^{3}\end{array}$ \\
\hline 40 & 30 & 179 & 374 & 764 & 352 & 703 \\
\hline
\end{tabular}

Notes: 1 . The target mean strength and slump were $53 \mathrm{MPa}$ and $150 \mathrm{~mm}$, respectively. 2 . The water/cement ratio was $0 \cdot 48$. 3. The fines/total aggregate ratio was $0 \cdot 42$. 4. A solid powder superplasticiser was added during concrete mixing until the slump of the concrete mix reached $150 \mathrm{~mm}$. 


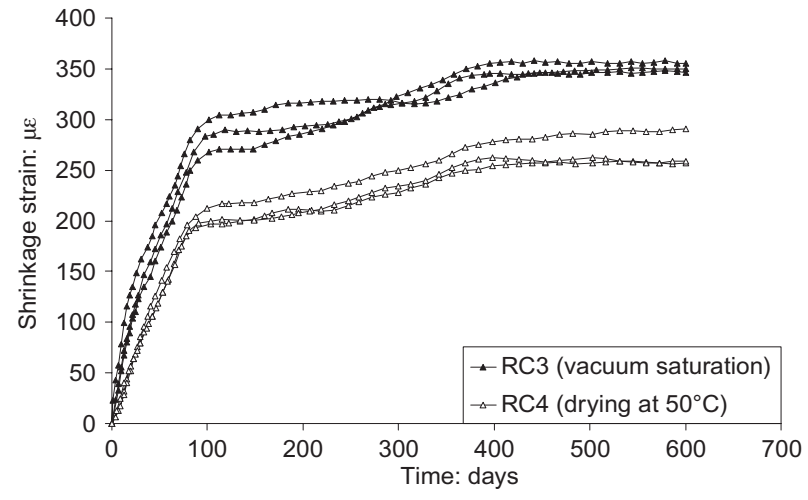

Figure 2. Shrinkage of rock cores $R C 3$ and $R C 4$

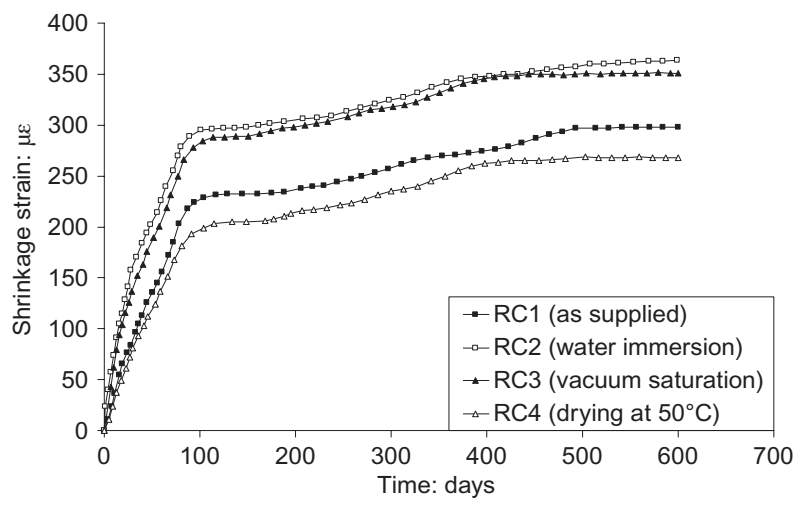

Figure 3. Average shrinkage strains of rock cores RC1 to $R C 4$

each shrinkage-time curve, the ultimate shrinkage is determined as the shrinkage strain at the end of the shrinkage test (after at least 600 days of drying shrinkage) and the shrinkage half-time is determined as the time taken for the shrinkage to reach half of the ultimate shrinkage. The ultimate shrinkage and shrinkage half-time of the rock cores tested are presented in Tables 3 and 4, respectively.

The above results show that for the rock cores tested, the ultimate shrinkage ranges from 257 to $381 \mu \varepsilon$, and the shrinkage half-time ranges from 37 to 64 days. These values of ultimate shrinkage are very substantial. Bearing in mind that the ultimate shrinkage of concrete is normally within the range $400-1000 \mu \varepsilon$, such measured shrinkage of the local granite rock amounts to at least one-third of the shrinkage of the concrete. The traditional belief that granite rock would not shrink is wrong. The plain fact is that not all granite rocks are non-shrinking. Particularly, for the case in Hong Kong, it is the shrinkage of the local granite rock that causes the large shrinkage of the concrete produced (Kwan et al., 2010).

On the other hand, the shrinkage half-time should be interpreted with respect to the size of the rock cores tested. The rock cores have a diameter of $60 \mathrm{~mm}$ and thus an effective thickness of $30 \mathrm{~mm}$ (the effective thickness is equal to two times the volume/exposed area ratio). In theory, the shrinkage half-time should increase with the effective thickness. Using the formula given in Eurocode 2, the shrinkage half-time for an effective thickness of $75 \mathrm{~mm}$, which will be used for later comparison between rock and concrete, may be evaluated as four times the shrinkage half-time for an effective thickness of $30 \mathrm{~mm}$. Hence, if the effective thickness is corrected to $75 \mathrm{~mm}$, the shrinkage halftime of the rock cores would range from 148 to 256 days.

It is also evident from Tables 3 and 4 that the initial moisture condition has significant effects on the ultimate shrinkage and shrinkage half-time. For the rock cores in RC1, which were untreated and simply stored in the laboratory before the wetting and drying for the shrinkage test, the average ultimate shrinkage strain

Table 3. Ultimate shrinkage of rock cores under different initial moisture conditions

\begin{tabular}{|c|c|c|c|c|c|}
\hline \multirow[t]{2}{*}{ Rock core designation } & \multirow{2}{*}{$\begin{array}{l}\text { Initial moisture } \\
\text { condition }\end{array}$} & \multicolumn{4}{|c|}{ Ultimate shrinkage strain: $\mu \varepsilon$} \\
\hline & & Specimen (a) & Specimen (b) & Specimen (c) & Average \\
\hline $\mathrm{RC} 1$ & As supplied & 310 & 284 & 299 & 298 \\
\hline $\mathrm{RC} 2$ & Water immersion & 331 & 381 & 373 & 362 \\
\hline $\mathrm{RC} 3$ & Vacuum saturation & 350 & 347 & 355 & 351 \\
\hline $\mathrm{RC} 4$ & Drying at $50^{\circ} \mathrm{C}$ & 257 & 289 & 259 & 268 \\
\hline
\end{tabular}

Table 4. Shrinkage half-time of rock cores under different initial moisture conditions

\begin{tabular}{l|l|c|c|c|c}
\hline \multirow{2}{*}{ Rock core designation } & $\begin{array}{l}\text { Initial moisture } \\
\text { condition }\end{array}$ & Specimen (a) & Specimen (b) & \multicolumn{3}{|c}{ Specimen (c) } \\
\cline { 3 - 5 } & & 46 & 64 & 38 \\
RC1 & As supplied & 47 & 42 & 40 \\
RC2 & Water immersion & 37 & 47 & 47 \\
RC3 & Vacuum saturation & 53 & 54 & 53 \\
RC4 & Drying at $50^{\circ} \mathrm{C}$ & & 53 & 43 \\
\hline
\end{tabular}


was $298 \mu \varepsilon$ and the average shrinkage half-time was 49 days. For the rock cores in RC2 and RC3, which were saturated with water before the shrinkage test, the average ultimate shrinkage strains were 362 and $351 \mu \varepsilon$, respectively, and the average shrinkage half-times were 43 and 44 days, respectively. Finally, for the rock cores in $\mathrm{RC} 4$, which were dried at $50^{\circ} \mathrm{C}$ before the wetting and drying for the shrinkage test, the average ultimate shrinkage strain was $268 \mu \varepsilon$ and the average shrinkage half-time was 53 days. Hence, quite obviously, the initially wet rock cores have larger ultimate shrinkage and shorter shrinkage half-time, whereas the initially dry rock cores have smaller ultimate shrinkage and longer shrinkage half-time. Comparing the ultimate shrinkage strains of the different rock cores, it may be worked out that the initial moisture condition could affect the ultimate shrinkage of the rock by up to $25 \%$.

\section{Shrinkage of concrete}

The water absorptions of the granite aggregate before and after treatment by immersion in polymer latex or water repellent have been measured and the results are presented in Table 5. It can be seen that without any treatment, the fine aggregate, $10 \mathrm{~mm}$ aggregate and $20 \mathrm{~mm}$ aggregate (i.e. those in A1) have water absorptions of $1.54,0.95$ and $0.76 \%$, respectively. After treatment by immersion in polymer latex for $6 \mathrm{~h}$ and then drying at $50^{\circ} \mathrm{C}$, the fine aggregate, $10 \mathrm{~mm}$ aggregate and $20 \mathrm{~mm}$ aggregate (i.e. those in B1) have water absorptions of $1.09,0.77$ and $0.59 \%$, respectively. Similarly, after treatment by immersion in water repellent for $6 \mathrm{~h}$ and then drying at $50^{\circ} \mathrm{C}$, the fine aggregate,

Table 5. Water absorption of aggregate

\begin{tabular}{l|c|c|c}
\hline \multirow{2}{*}{$\begin{array}{l}\text { Aggregate } \\
\text { designation }\end{array}$} & \multicolumn{3}{|c}{ Water absorption: \% } \\
\cline { 2 - 4 } & Fine aggregate & $\begin{array}{c}10 \mathrm{~mm} \\
\text { aggregate }\end{array}$ & $\begin{array}{c}20 \mathrm{~mm} \\
\text { aggregate }\end{array}$ \\
\hline A1 & 1.54 & 0.95 & 0.76 \\
B1 & 1.09 & 0.77 & 0.59 \\
B2 & 1.06 & 0.77 & 0.67 \\
\hline
\end{tabular}

$10 \mathrm{~mm}$ aggregate and $20 \mathrm{~mm}$ aggregate (i.e. those in B2) have water absorptions of $1.06,0.77$ and $0.67 \%$, respectively. Hence, by immersing the aggregate in polymer latex or water repellent for $6 \mathrm{~h}$, the water absorption of the aggregate can be significantly reduced. This indicates that the polymer latex and water repellent are effective in filling the pores in the aggregate to block or slow down the ingress of water when the aggregate is wetted.

The 28-day cube compressive strengths of the six concrete mixes have been measured and the results are presented in Table 6. All the concrete mixes have achieved a mean cube compressive strength of at least 51.4 MPa. Hence, the various treatments applied to the aggregate have little effect on the concrete strength. Although the treatments applied to the aggregates in B1 and B2 appear to have a certain effect on the concrete strength, there should be no difficulty in making up such slight reduction in concrete strength by lowering the water/cement ratio of the concrete mix.

The shrinkage-time curves of the concrete prisms cast from the concrete mixes CON1, CON2, CON3, CON4, CON5 and CON6 are presented in Figures 4, 5, $6,7,8$ and 9, respectively. For each concrete mix, the shrinkage-time curves of all the four prisms cast are plotted in these figures. In all cases, the shrinkagetime curves of the prisms cast from the same concrete mix are fairly close to each other, with differences in the measured shrinkage strain generally less than $100 \mu \varepsilon$. Hence, it may be said that the measured results

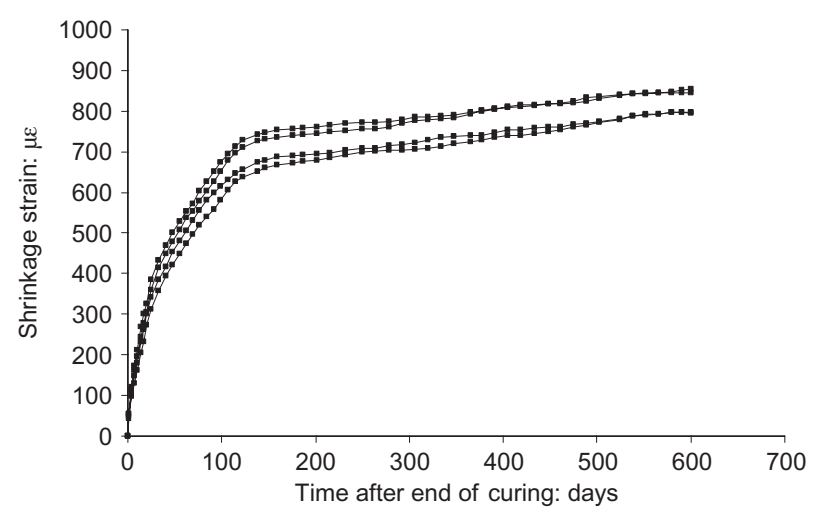

Figure 4. Shrinkage of concrete mix CON1 (Al aggregate used)

Table 6. Cube compressive strength of concrete mixes

\begin{tabular}{l|l|c|c|c}
\hline \multirow{2}{*}{ Concrete mix designation } & Aggregate used & \multicolumn{3}{|c}{ 28-day cube compressive strength: MPa } \\
\cline { 3 - 5 } & & Specimen (1) & Specimen (2) & Specimen (3)* \\
\hline CON1 & & $56 \cdot 4$ & $57 \cdot 7$ & $57 \cdot 0$ \\
CON2 & A1 & $52 \cdot 5$ & $53 \cdot 9$ & $52 \cdot 0$ \\
CON3 & A2 & $57 \cdot 6$ & $57 \cdot 9$ & $57 \cdot 3$ \\
CON4 & A3 & $52 \cdot 7$ & $53 \cdot 9$ & $51 \cdot 3$ \\
CON5 & A4 & $50 \cdot 6$ & $52 \cdot 2$ & $57 \cdot 6$ \\
CON6 & B1 & $52 \cdot 0$ & $52 \cdot 3$ & $52 \cdot 6$ \\
\hline
\end{tabular}

*Specimen (3) of CON5 was damaged during handling. 


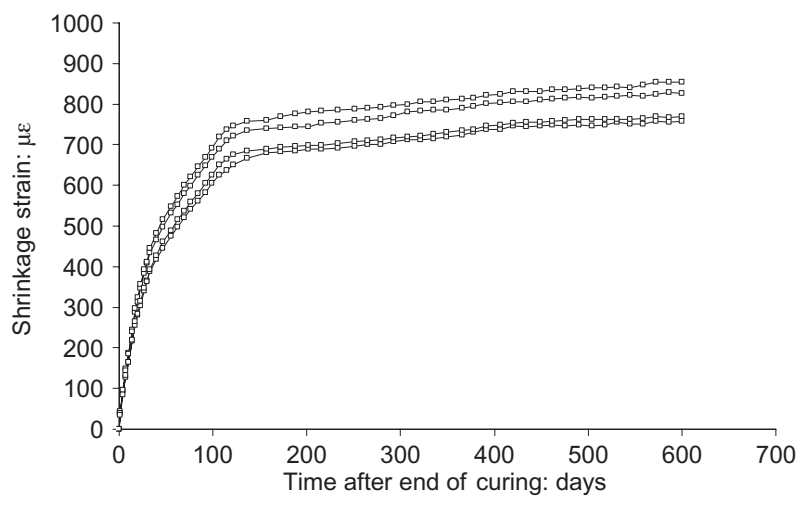

Figure 5. Shrinkage of concrete mix CON2 (A2 aggregate used)

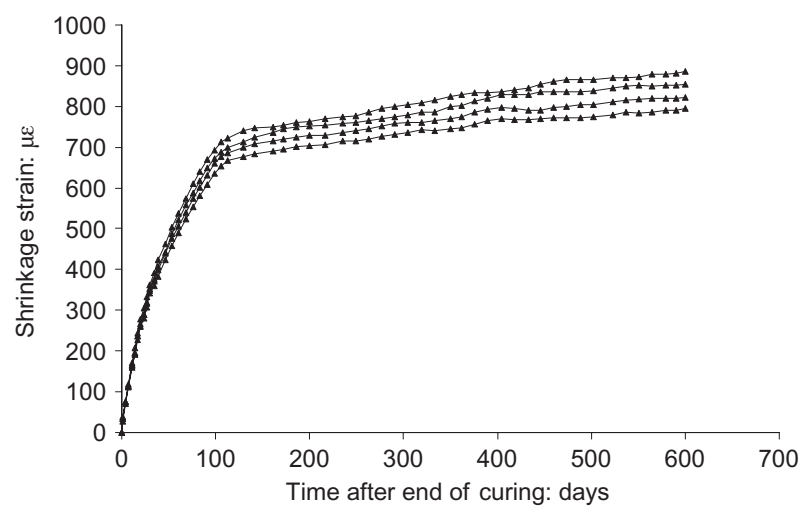

Figure 6. Shrinkage of concrete mix CON3 (A3 aggregate used)

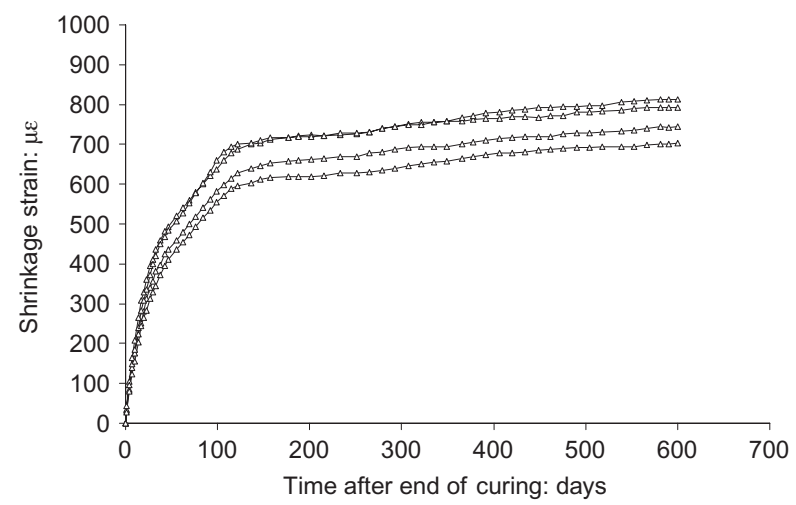

Figure 7. Shrinkage of concrete mix CON4 (A4 aggregate used)

are reasonably consistent. For easier interpretation, the shrinkage strains of the four prisms cast from each concrete mix are averaged to yield the average shrinkage-time curves of the six concrete mixes in Figure 10.

Like that of the rock cores, the shrinkage of the concrete prisms also increased with time initially at a rapid rate and then at a gradually decreasing rate. From each shrinkage-time curve, the ultimate shrinkage (the shrinkage strain after at least 600 days of drying) and the shrinkage half-time (the time taken for half of the 440

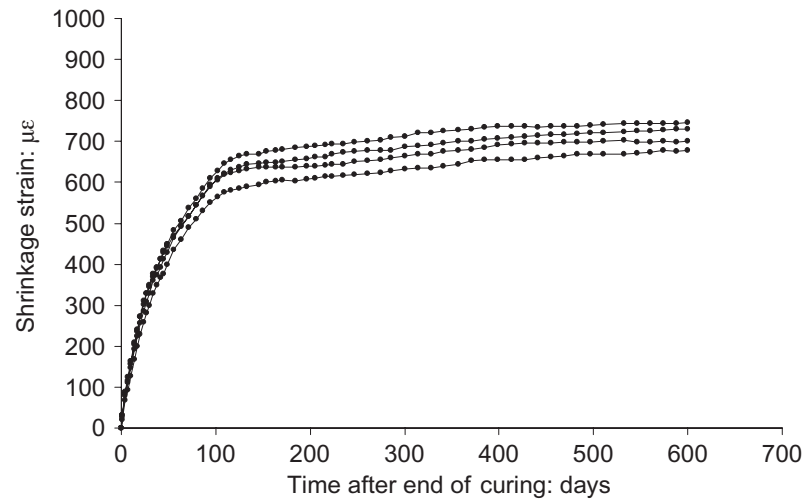

Figure 8. Shrinkage of concrete mix CON5 (B1 aggregate used)

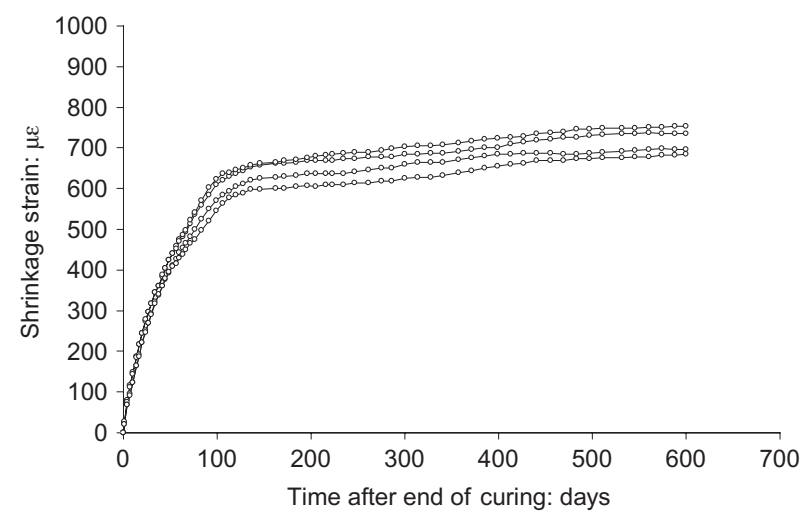

Figure 9. Shrinkage of concrete mix CON6 (B2 aggregate used)

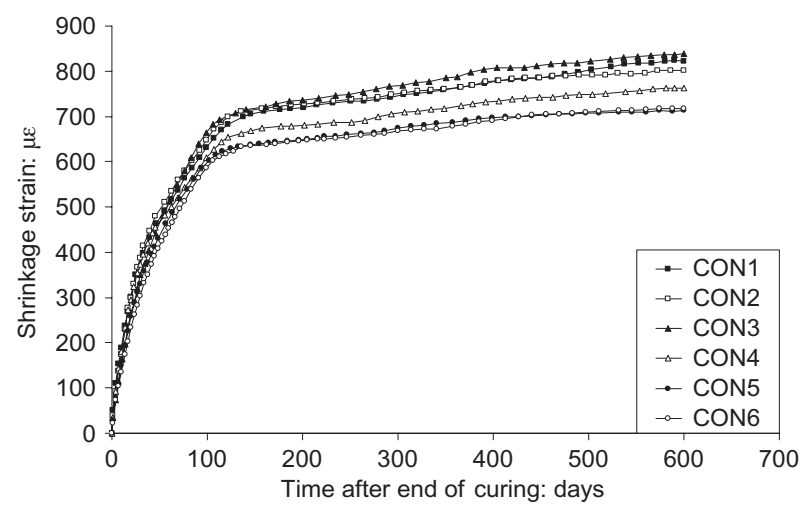

Figure 10. Average shrinkage strains of concrete mixes CON1 to CON6

ultimate shrinkage to take place) are determined, as presented in Tables 7 and 8 .

The above results show that for the concrete mixes made with the aggregates from A1, A2, A3 or A4 (aggregates which had not been treated by the proposed methods of immersion in polymer latex or water repellent), the ultimate shrinkage ranges from 701 to $885 \mu \varepsilon$ while the shrinkage half-time ranges from 27 to 42 days. These results are similar to the previous results obtained by the authors in an earlier study on the shrinkage of Hong Kong granite aggregate concrete

Magazine of Concrete Research, 2010, 62, No. 6 
Table 7. Ultimate shrinkage of concrete mixes

\begin{tabular}{l|l|c|c|c|c}
\hline \multirow{2}{*}{$\begin{array}{l}\text { Concrete mix } \\
\text { designation }\end{array}$} & \multirow{2}{*}{ Aggregate used } & \multicolumn{4}{|c}{ Ultimate shrinkage strain: $\mu \varepsilon$} \\
\cline { 3 - 6 } & & Specimen (i) & Specimen (ii) & Specimen (iii) & Specimen (iv) \\
\hline CON1 & A1 & 851 & 846 & 798 & 794 \\
CON2 & A2 & 779 & 827 & 853 & 788 \\
CON3 & A3 & 855 & 885 & 794 & 822 \\
CON4 & A4 & 742 & 795 & 815 & 703 \\
CON5 & B1 & 744 & 731 & 701 & 671 \\
CON6 & B2 & 735 & 753 & 697 & 712 \\
\hline
\end{tabular}

Table 8. Shrinkage half-time of concrete mixes

\begin{tabular}{|c|c|c|c|c|c|c|}
\hline \multirow{2}{*}{$\begin{array}{l}\text { Concrete mix } \\
\text { designation }\end{array}$} & \multirow[t]{2}{*}{ Aggregate used } & \multicolumn{5}{|c|}{ Shrinkage half-time: days } \\
\hline & & Specimen (i) & Specimen (ii) & Specimen (iii) & Specimen (iv) & Average \\
\hline CON1 & A1 & 36 & 31 & 41 & 36 & 36 \\
\hline CON2 & $\mathrm{A} 2$ & 33 & 32 & 32 & 33 & 33 \\
\hline CON3 & A3 & 42 & 42 & 41 & 41 & 42 \\
\hline CON4 & A4 & 32 & 27 & 32 & 32 & 31 \\
\hline CON5 & B1 & 33 & 35 & 31 & 37 & 34 \\
\hline CON6 & B2 & 39 & 40 & 40 & 40 & 40 \\
\hline
\end{tabular}

(Kwan et al., 2010). It should be noted that the shrinkage of these concrete mixes made with the local granite aggregate is on average quite large. Furthermore, the shrinkage of the concrete is to some extent dependent on the initial moisture condition of the aggregate. For instance, the concrete mixes CON1, CON2 and CON3 made with as supplied or saturated aggregates have average ultimate shrinkage strains of about $824 \mu \varepsilon$, while the concrete mix CON4 made with pre-dried aggregate has an average ultimate shrinkage strain of $764 \mu \varepsilon$, which is about $60 \mu \varepsilon$ or $7 \%$ smaller.

The above results also show that for the concrete mixes made with the aggregates from B1 or B2 (aggregates which had been treated by the proposed methods of immersion in polymer latex or water repellent), the ultimate shrinkage ranges from 671 to $753 \mu \varepsilon$ while the shrinkage half-time ranges from 31 to 40 days. Specifically, the concrete mix CON5 made with the aggregates from B1 has an average ultimate shrinkage strain of $712 \mu \varepsilon$ while the concrete mix CON6 made with the aggregates from B2 has an average ultimate shrinkage strain of $717 \mu \varepsilon$. Compared to that of CON1 made with as supplied aggregate, the average ultimate shrinkage strain of CON5 is $110 \mu \varepsilon$ smaller, while the average ultimate shrinkage strain of CON6 is $105 \mu \varepsilon$ smaller. Hence, the proposed aggregate treatments of immersion in polymer latex or water repellent and then drying can reduce the concrete shrinkage by about $13 \%$.

On the other hand, the shrinkage half-time results indicate that both the initial moisture condition of the aggregate and the treatment applied to the aggregate have no obvious effects on the shrinkage half-time of the concrete produced. For comparison, it is noteworthy that after correcting to an effective thickness of $75 \mathrm{~mm}$, the shrinkage half-time of the concrete prisms tested ranges from 27 to 42 days while the shrinkage halftime of the rock cores tested ranges from 148 to 256 days. So, generally speaking, the granite rock shrinks at a slower rate than the concrete. It may thus be inferred that the effects of the shrinkage of the granite aggregate on the shrinkage of the concrete are larger at the later age than at the early age of the concrete.

Although the $13 \%$ reduction in concrete shrinkage by the proposed aggregate treatments of immersion in polymer latex or water repellent and then drying does not appear to be very effective, it is already a good start because the proposed treatment methods are still rudimentary. There is great potential for improvement. Some suggestions are as follows.

(a) Extend the immersion period from $6 \mathrm{~h}$ to at least $24 \mathrm{~h}$ so that more pores inside the rock aggregate would be filled with the polymer latex or water repellent.

(b) Apply vacuum during immersion so that even the finest pores deep inside the rock aggregate would be filled with the polymer latex or water repellent.

(c) Dry the treated aggregate at higher temperature and/or for a longer period of time so that the initial moisture condition of the rock aggregate would be drier.

Further research is needed to improve the proposed aggregate treatment technology. Another possibility is to combine such aggregate treatment with the addition of a shrinkage reducing admixture (Folliard and Berke, 1997) to the concrete mix so as to reduce not only the 
shrinkage of the aggregate but also the shrinkage of the hardened cement paste.

\section{Conclusions}

In the first part of the testing program, the shrinkage of the granite rock in Hong Kong has been measured in the form of rock cores under different initial moisture conditions. It was found that the granite rock, which is commonly used as aggregate for making concrete, could shrink by up to $380 \mu \varepsilon$. Hence, the granite aggregate in Hong Kong is a shrinking aggregate. This is in fact the main reason for the large shrinkage of the Hong Kong granite aggregate concrete. Clearly, the conventional wisdom that granite aggregate will not shrink is not universally applicable. It was also found that the shrinkage of the granite rock is dependent on the initial moisture condition. In general, granite rock that is initially wet has larger ultimate shrinkage and shorter shrinkage half-time, whereas granite rock that is initially dry has smaller ultimate shrinkage and longer shrinkage half-time.

In the second part of the testing programme, the shrinkage of concrete mixes cast from aggregates with different initial moisture conditions and concrete mixes made with aggregates treated by immersion in polymer latex or water repellent for $6 \mathrm{~h}$ and then drying at $50^{\circ} \mathrm{C}$ has been measured in the form of concrete prisms. The results revealed that the initial moisture condition of the aggregate has certain effects on the shrinkage of the concrete and that pre-drying of the aggregate could slightly reduce the shrinkage of the concrete by about $7 \%$. Such pre-drying of the aggregate is not very effective because the aggregate would become wet again when mixed with the water in the concrete mix. The results also revealed that the proposed treatments by immersion in polymer latex or water repellent and then drying could reduce the water absorption of the aggregate significantly and thereby reduce the shrinkage of the concrete by about $13 \%$. Bearing in mind that this was just a first attempt, the $13 \%$ reduction in concrete shrinkage should be regarded as promising. Although such effectiveness is not really satisfactory, there is good potential for improvement. For instance, the treatment methods may be improved by extending the immersion period, applying vacuum during immersion and drying the immersed aggregate at higher temperature for a longer time. There is also the possibility of combining the proposed aggregate treatments with the addition of a shrinkage-reducing admixture to the concrete mix. Further studies along these lines are recommended.

\section{Acknowledgement}

The work described in this paper was fully supported by a grant from the Research Grants Council of the Hong Kong Special Administrative Region, China (project No. HKU 713107E).

\section{References}

ACI (American Concrete Institute) (2008) ACI 209.2R-08: Guide for modelling and calculating shrinkage and creep in hardened concrete. ACI Committee 209, American Concrete Institute, Farmington Hills, MI.

Alexander M and Mindess S (2005) Aggregates in hardened concrete: physical and mechanical properties. In Aggregates in Concrete, Modern Concrete Technology Series. Taylor \& Francis, London, UK, Ch. 5, pp. 223-295.

Ayano T and Wittmann FH (2002) Drying, moisture distribution, and shrinkage of cement-based materials. Materials and Structures 35(3): 134-140.

Barr B, Hoseinian SB and Beygi MA (2003) Shrinkage of concrete stored in natural environments. Cement and Concrete Composites 25(1): $19-29$.

Bazant ZP, Wittmann FH, Kim JK and Alou F (1987) Statistical extrapolation of shrinkage data - Part I: Regression. ACI Materials Journal 84(1): 20-34.

Bissonnette B, Pierre P and Pigeon M (1999) Influence of key parameters on drying shrinkage of cementitious materials. Cement and Concrete Research 29(10): 1655-1662.

Bloom R and Bentur A (1995) Free and restrained shrinkage of normal and high-strength concretes. ACI Materials Journal 92(2): 211-217.

BSI (British Standards Institution) (1989) BS 812: Testing aggregates: Part 120: 1989: Methods for testing and classifying drying shrinkage of aggregates in concrete. British Standards Institution, Milton Keynes, UK.

BSI (1990) BS 5400: Part 4: 1990: Code of practice for design of concrete bridges. British Standards Institution, Milton Keynes, UK.

BSI (1995) BS 812: Testing aggregates: Part 2: 1995: Methods of determination of density. British Standards Institution, Milton Keynes, UK.

BSI (2004) BS EN 1992-1-1: 2004, Eurocode 2: Design of concrete structures. Part 1-1: General rules and rules for buildings. British Standards Institution, Milton Keynes, UK.

CEB-FIP (Comité Euro-International du Béton-Fédération Internationale de la Précontrainte) (1993) CEB-FIP Model Code 1990: Model Code for Concrete Structures. Thomas Telford, London, UK.

Folliard KJ and Berke NS (1997) Properties of high-performance concrete containing shrinkage-reducing admixture. Cement and Concrete Research 27(9): 1357-1364.

Hansen W and Almudaiheem JA (1987) Ultimate drying shrinkage of concrete - influence of major parameters. ACI Materials Journal 84(3): $217-223$.

Highways Department (2002) Structures Design Manual for Highways and Railways, 2002 edn. Government of the Hong Kong Special Administrative Region, Hong Kong, China.

Highways Department (2006) Structures Design Manual for Highways and Railways, 2006 edn. Government of the Hong Kong Special Administrative Region, Hong Kong, China.

Kim HS and Cho SH (2004) Shrinkage stress analysis of concrete slabs with shrinkage strips in a multistorey building. Computers and Structures 82(15-16): 1143-1152.

Kwan AKH, Au FTK and Lee PKK (2002) Minimizing shrinkage cracks in concrete structures for better serviceability and durability. Proceedings of the Innovative Buildings Symposium, Hong Kong, pp. 117-136.

Kwan AKH, Au FTK, Wong HHC and Ng PL (2010) Shrinkage of Hong Kong granite aggregate concrete. Magazine of Concrete Research, 62(2): 115-126, doi: 10.1680/macr.2010.62.2.115.

Lee PKK, Kwan AKH and Zheng W (2000) Tensile strength and elastic modulus of typical concrete made in Hong Kong. Transactions of the Hong Kong Institution of Engineers 7(2): 35-40.

Discussion contributions on this paper should reach the editor by 1 December 2010

Magazine of Concrete Research, 2010, 62, No. 6 